\title{
Perceptions and Attitudes of University Students of Five Mexican Public Institutions on the Labeling of Products Made with Genetically Modified Organisms
}

\author{
Emeterio Franco-Pérez ${ }^{1}$, Osval Antonio Montesinos-López ${ }^{2}$ J Jesús García Martínez ${ }^{3}$, Alberto Pastrana Palma ${ }^{4}$, \\ Josafhat Salinas-Ruiz ${ }^{5} \&$ Sara Sandoval Carrillo ${ }^{2}$ \\ ${ }^{1}$ School of Marketing, University of Colima, Mexico \\ ${ }^{2}$ Faculty of Telematics, University of Colima, Mexico \\ ${ }^{3}$ Faculty of Accounting and Administration, University of Colima, Mexico \\ ${ }^{4}$ Faculty of Engineering, Autonomous University of Queretaro, Mexico \\ ${ }^{5}$ Colegio de Postgraduados, Campus Córdoba, Mexico \\ Correspondence: Emeterio Franco-Pérez- School of Marketing, University of Colima. Av. Universidad 333, Col. \\ Las Víboras, C.P. 28040, Colima, Mexico. E-mail: francoperez@ucol.mx
}

\begin{abstract}
Introduction: To know the perceptions and attitudes about the labeling of products made with genetically modified organisms (GMO), of students from five universities in central Mexico, in the following areas of knowledge: natural sciences, health sciences, chemical sciences, economic and administrative sciences and biological and agricultural sciences. Methodological design and approach: In the study, 2923 students answered a questionnaire with Likert scale of five questions. It is important to mention that the original questionnaire has 64 variables and 11 factors to measure the perceptions, attitudes, benefits and risks on the production and consumption of GMO. Results: Of the total sample $16.60 \%$ always read the labels, $85.70 \%$ agree that the label should show the characteristics of the product. $82.90 \%$ said that when making promotions should be reported on the label the characteristics of the product and finally $82.90 \%$ answered that the Mexican government should legislate a legal framework to regulate the mandatory labeling of products made with GMOs. Discussion or Conclusion. The sample only cover 5 Mexican universities. The relevant contribution of this research provides an empirical knowledge about the perceptions and attitudes regarding the labeling of products with GMOs content from a sample of the population of five public universities in central Mexico. This study is an important contribution for Mexican society, because there is no legal framework to regulate the labeling of products with GMO content and that it is essential to strengthen the training of university students with scientific information in this field. The labeling of products made with GMOs is generating relevant controversies worldwide, so it is important to know and spread the perceptions and attitudes of the sample considered in this study.
\end{abstract}

Keywords: Labeling, products with GMO, university students, perception

\section{Introduction}

The labeling of products for human consumption is widely used throughout the world, which covers a wide range of attributes with relevant information for producers, government institutions, wholesalers, retailers and the final consumer.

The labeling of the products in the world can be of two types: the voluntary and the mandatory. It is relevant to point out that in the last two decades the controversy has increased over the labeling of products for human consumption made with plants and animals that have been genetically modified (GM), in relation to the labeling of conventional and organic products ( Meemken \& Matin, 2018).

In the European Economic Community (EU) since 2003, the first policies were formulated on the labeling of products with GMO content (de Beer \& Wynberg, 2018). A legal framework has been legislated, with which standards have been established to regulate the labeling of products with GMO content for human consumption, 
to such a degree that no product should contain a contamination threshold higher than $0.9 \%$ (Venus, et al., 2016). However, in the United States of America there has not been the same interest, to such a degree that in some of the states that make up this country, has not legislated in this matter. But, the case of the state of Connecticut is an example being the first to legislate in this regard ( Bovay \& Alstonb, 2018). In response to the US social pressure and in order to avoid inconsistencies in this area, President Barack Obama signed an initiative of law with the number S. 764 (Castellari, et al., 2018) which was approved by Congress with the number PL 114-216 and assigned to the United States Department of Agriculture (USDA). This Department will formulate the corresponding regulation on the labeling of products made with plants and animals that have been modified with GMOs (Bovay \& Alstonb, 2018). However, the regulation formulated by the USDA and made known to the American society (Bovay \& Alstonb, 2018) has polarized this population (Center for Food Safety, 2018). It is important to mention that there are currently 64 countries, including members of the European Economic Community, Russia, Brazil, Australia, Turkey, South Africa and China, that had established standards to label products with GMO content (Center for Food Safety, 2018). To date, the Mexican government, has not legislated the corresponding legal framework for products with GMO to be labeled on a mandatory basis, it is important to give Mexicans the power to decide which kind of products they want to buy. In 2017, the Ministry of Health in Mexico asked the National Institute of Public Health (INSP) to set up a group of academic experts in labeling, independent and free of conflicts of interest. Their job was to issuing a position to contribute to the development of a labeling system for industrialized products that provides useful information to facilitate the purchase decision (Committee of National Academic Experts of Front Food Labeling, 2018). However, in the article published by the working group there is no evidence that the topic of the labeling of foods made with plants and animals with GMO has been addressed.

It is relevant to point out that in 2015 a research was carried out in Mexico, at a national level, to know the perceptions and attitudes towards GMOs financed by the National Council of Science and Technology (CONACYT), with a sample of 14720 participants from the Mexican urban population, with people in a range of age between 18 to 65 years, in this study all 64 items of the questionnaire were dichotomous (Montesinos-López, et al., 2016). From the results of this survey these authors published a paper about the attitudes toward labeling of genetically modified products (Montesinos-López, et al., 2017), were they reported that $63.25 \%$ of the participants has the habit of reading the labels of the products that they consume. Also, they reported that $93.69 \%$ participants said that when companies advertise these types of products, they must show on the label the characteristics of the content, $93.59 \%$ want that products made with GMO show the characteristics of the content on the label and finally $93.23 \%$ agree that the Mexican government must legislate the corresponding legal framework, to force companies to label products with GMO content (Montesinos-López, et al., 2017).

For this reason, in this paper the main goal is to study the perceptions and attitudes of university students of five Mexican public institutions on the labeling of products made with genetically modified organisms.

\section{Materials and Methods}

\subsection{Instrument and Sample of Participants}

The instrument used for this research was of four questions with Likert scale (nothing, rarely, sometimes, frequently and always), with the following items:

1. Do you have the habit of reading the labels of the products your family consumes in the diet, before buying them?

2. Do you consider that transgenic products must show, on their label, the corresponding information?

3. Do you consider that in the promotion of transgenic products it is important to inform the consumer about its content?

4. Do you consider that the Mexican government should generate laws to regulate the labeling of transgenic products?

In addition to this four items we also asked to the students the following aspects: area of knowledge of their professional career, semester, age, gender, among other sociodemographic variables. The questionnaire used have four variables and it was applied to a non-probabilistic sample of 2923 students of five public universities of central Mexico.

The four variables (items) that were measured in relation to the labeling for this article, are part of the original questionnaire with 64 variables and 11 factors latent, which was designed to measure perceptions, attitudes, benefits and risks on the production and consumption of GMOs of university students of 5 Mexican public universities of central México. 


\subsection{Description of Participants}

For the treatment of the data, we only did a descriptive analysis of the information collected. The students belong to five public universities in central Mexico, according to the following data: Autonomous University of San Luis Potosí (UASLP) 451 students (15.40\%), University of Colima (UDEC) 523 students $(17.90 \%$ ), Autonomous University of Aguascalientes (UAA) 546 students (18.70\%), Autonomous University of Querétaro (UAQ) 587 students (20.10\%), and finally at the University Michoacana of San Nicolas de Hidalgo (UMSH) 816 students $(27.90 \%)$. Figure 1 shows the distribution.

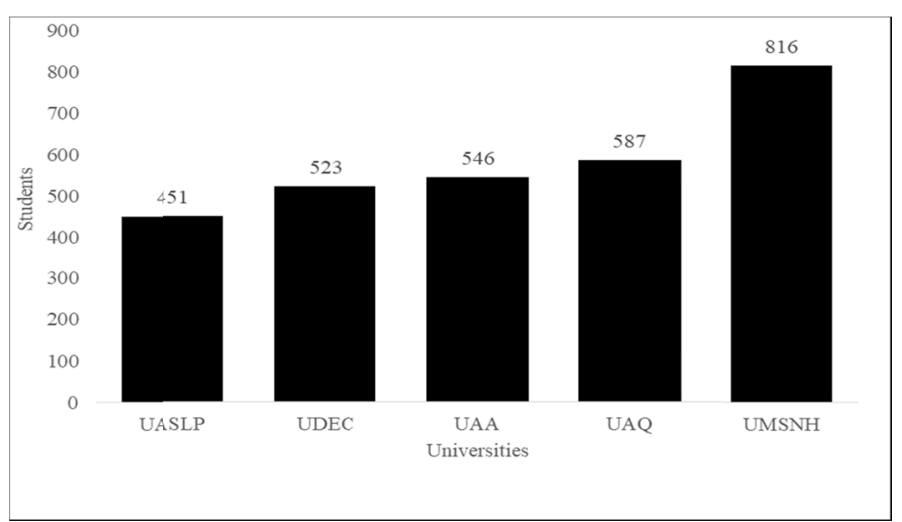

Figure 1. Distribution of the non-probabilistic sample collected in the five universities of central Mexico. Source: prepared by the authors

It is relevant to point out that the sample of students surveyed from the reference universities are from the following areas of knowledge: natural sciences (Natural) 3 students $(0.10 \%)$, chemical sciences (Chemical) 62 students (2.12\%), economic and administrative sciences (Economic and administrative Sciences) 558 students (19.08), biological and agricultural sciences (Biological and agronomy) 911students (31.16\%), and finally health sciences (Health) 1389 students (47.51\%). Figure 2 shows the distribution.

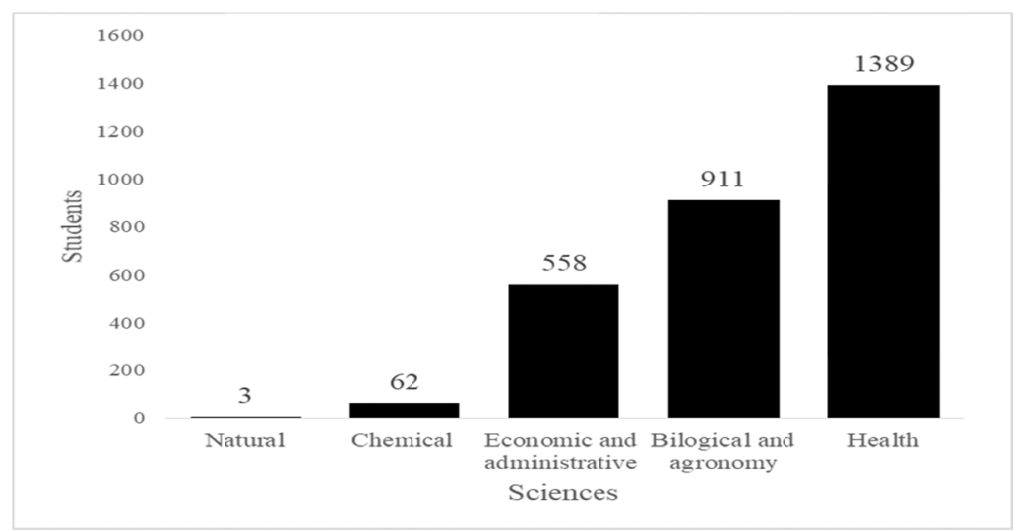

Figure 2. Students surveyed by area of knowledge of the five public universities of central Mexico

Source: prepared by the authors.

The percentages of the students by age who participated in the research are described below: from 18 years of age were surveyed 24 students (1\%), with 19 years 512 students (18\%), with 20 years 672 students (23\%), with 21 years 781 students (27\%), with 22 years old or more 934 students (32\%) as shown in figure 3. 


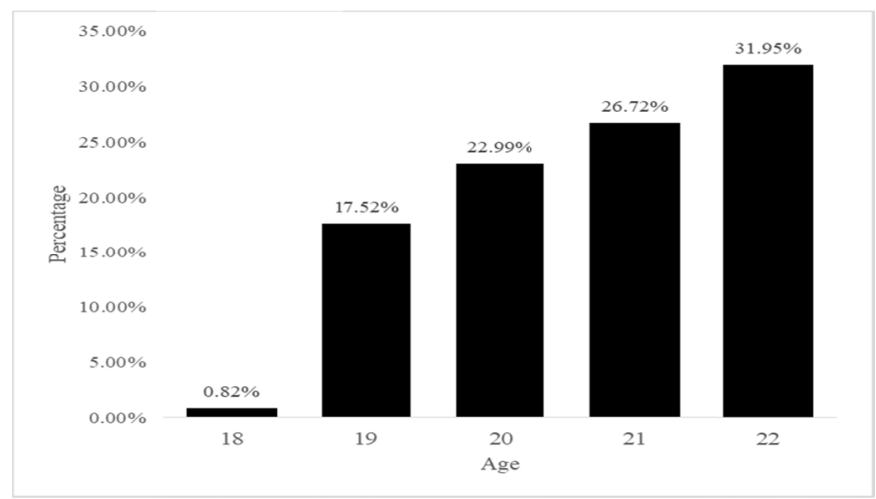

Figure 3. Students by age and percentage who participated in this research

Source: prepared by the authors.

In relation to the semester students were studying, the results are shown below: in the first semester the questionnaire was applied to 34 students $(1.16 \%)$, in the second semester to 40 students $(1.37 \%)$, in 3 rd semester to 181 students $(6.19 \%)$. In 4 th semester to 31 students $(1.06 \%)$, in $5^{\text {th }}$ semester to 499 students $(17.07 \%)$, in 6 th semester to 298 students $(10.20 \%)$, in 7 th semester to 634 students $(21.69 \%)$, in 8 th semester to 577 students (19.74\%), in 9th semester to 526 students $(18.00 \%)$, in 10th semester to 103 students (3.52\%). Figure 4 shows the distribution.

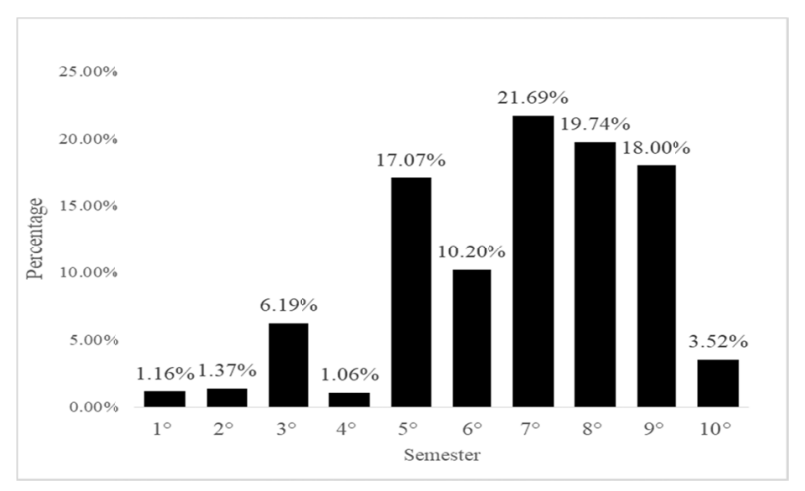

Figure 4. Students (and percentage) of the sample per semester

Source: prepared by the authors.

The distribution of students by gender was as follows: women (female) 1750 students (59.9\%) and men (male) 1173 students (40.1), as shown in Figure 5.

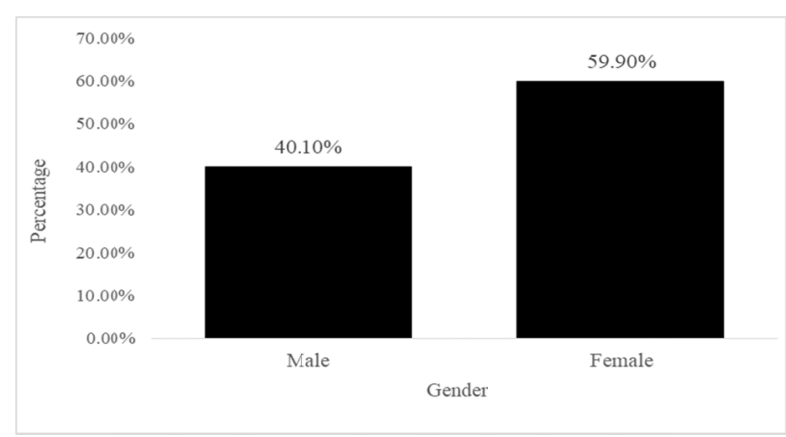

Figure 5. Distribution of the sample by gender of the students from the five universities of central Mexico Source: prepared by the authors. 


\section{Results}

In relation to the non-probabilistic sample of the 2923 students of the five universities of central Mexico that integrated this study, the results of each of the four questions, formulated for the purpose of research, are presented below, in relation to the labeling of the products made with GMOs.

Considering the first question, about whether the student has the habit of reading the labels before buying the products their family consumes, it was found that $6.40 \%$ of them never read the labels, $22.20 \%$ said that they rarely read them, $29.80 \%$ occasionally read the labels, while $25.00 \%$ frequently read the information on the labels, and finally $16.60 \%$ said they always read the labels. Figure 6 shows the distribution. The results of this research are consistent with the study carried out in several faculties of the University of Kuwait (Nedaa \& Al, 2018), considering a sample of 1000 students, of which 700 were men and 300 women. They were asked about the habit of reading labels before buying the products they consume in the daily diet, and mentioned the following: the $(20.80 \%)$ of the sample never read the labels, the $(46.20 \%)$ sometimes, $(23.40 \%)$ frequently and $(9.60 \%)$ always read the labels. As can be seen even when the sample of both investigations is made with university students of faculties or schools of medicine, nutrition, engineering, veterinary, agronomy, administration and arts the final result is that the amount or percentage of students who read the labels is low in both studies.

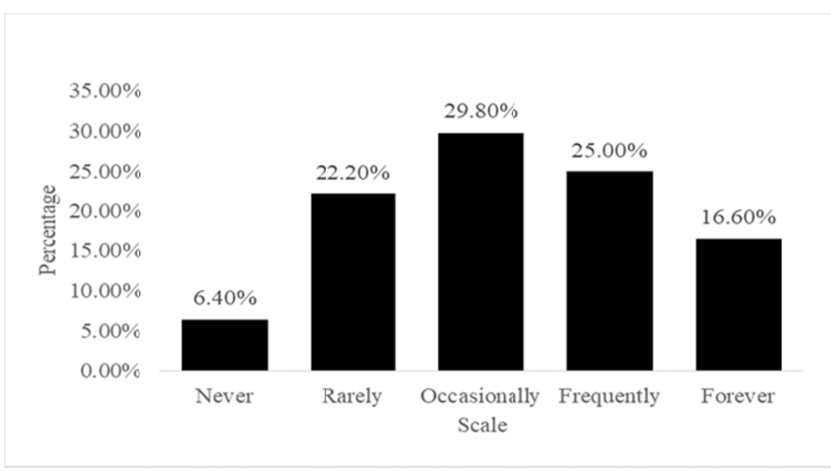

Figure 6. Do you have the habit of reading the labels of the products your family consumes in the diet, before buying them?

Source: prepared by the authors.

Regarding the second question asked, the results were the following: $0.50 \%$ answered that the products should never show the information in the label. $1.60 \%$ replied that they should seldom display the information on the label; on the other hand, $3.70 \%$ replied that they should occasionally show the characteristics of the product content on the label, while $8.50 \%$ said that the characteristics of the content of the product must often be shown. The most important thing is that $85.70 \%$ of the total sample wants that products made with GMOs always show on the label the characteristics of the content, as shown in figure 7.

The results of this research are consistent with the study conducted in India with university students, considering a sample of 298 students, were they found that $58 \%$ agree that food with GMO content should show information about the content of the product on the label to inform the final consumer (Kajale \& Biecker, 2013). Also, the research conducted in Russia with a sample of 300 university students, found that $83.33 \%$ said that products made with GMO should show the characteristics of the product in the labeling (Delmond, et al., 2018). 


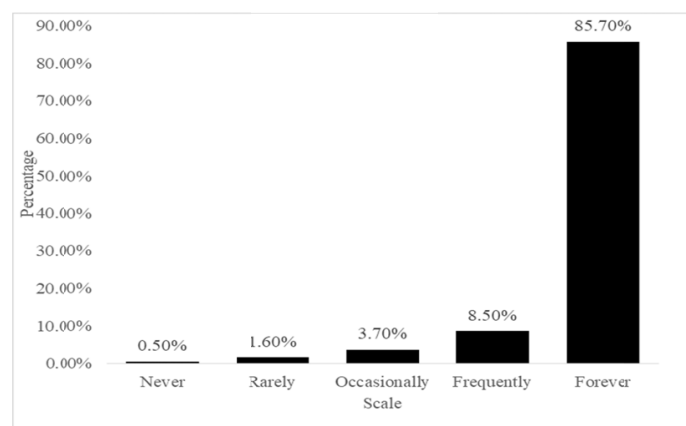

Figure 7: Do you consider that transgenic products should show, on their label, the corresponding information? Source: prepared by the authors.

Regarding the third question, the respondents considered that in the promotion of transgenic products it is vital to inform the consumer about the characteristics of the content. We found that $0.70 \%$ answered that it should never be reported on the label on the content of the product, while $2.40 \%$ said that the consumer should rarely be informed about its content. On the other hand, $4.70 \%$ said that occasionally they should be informed, as well as $9.30 \%$ said that they should frequently be informed and finally $82.90 \%$ revealed that they should always inform when promotion or advertising of this type of products to the final consumer about the content of the product you consume in your daily diet. As you can see in Figure 8.

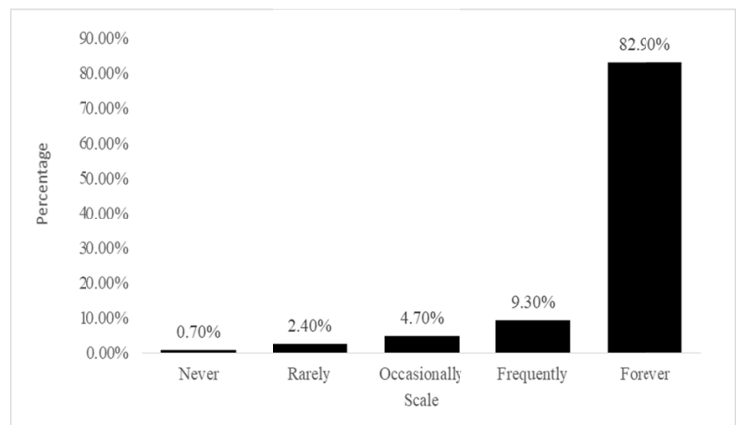

Figure 8. Do you think that in the promotion of transgenic products it is important to inform the consumer about its content?

Source: prepared by the authors.

Finally, when the respondents were asked if they considered that the Mexican government should generate laws to regulate the labeling of transgenic products, the sample expressed the following: $0.90 \%$ stated that the Mexican government should never regulate the labeling of the products with GMO, 2.00\% expressed that legislation should rarely be legislated in this matter, $4.70 \%$ thought that it should occasionally be regulated, while $9.60 \%$ said that should often be legislated in this matter, and finally $82.90 \%$ agree that the Mexican government must legislate a legal framework to regulate the labeling of products made with GMO, as shown in figure 9 . 


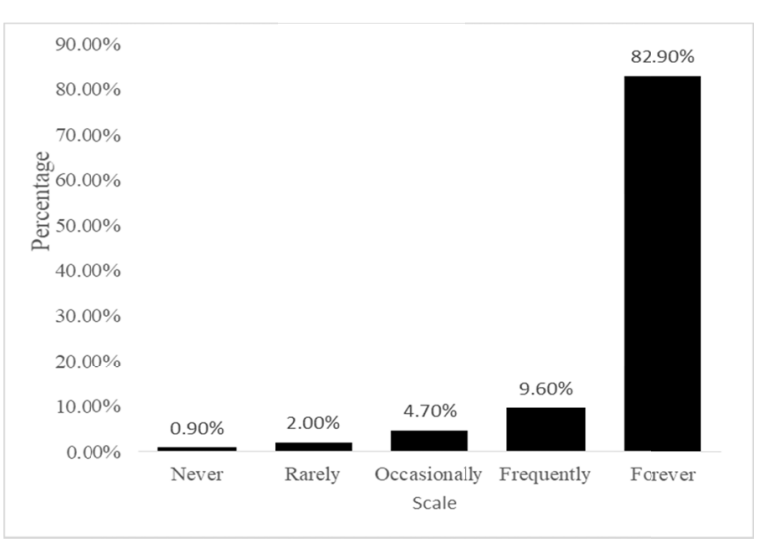

Figure 9. Do you consider that the Mexican government should generate laws and to regulate the labeling of transgenic products?

Source: prepared by the authors.

\section{Discussion}

In Mexico, the federal government has not created the legal framework to regulate the labeling of products with GMO. On February 11, 2016 an initiative of law called "Law for the Labeling of Foods of the Organic and Transgenic Category" was presented in the Chamber of Deputies (Ramírez Nachi, et al., 2016), and was discarded on October 11, 2018. This initiative states that $98 \%$ of Mexicans believe that companies that produces food with GMO should inform their consumers on the labels about the content of the product (Ramírez Nachi et al., 2016).

The initiative becomes important since according to the research conducted by Elena Âlvarez-Buylla, $82 \%$ of corn products from supermarkets and $90.4 \%$ of tortillas that Mexicans consume daily in the metropolitan area Mexico City, contains an undetermined degree genetically modified corn (González-Ortega et al., 2017). This results are relevant since the food of Mexicans is supported by corn. Transgenic corn began to be imported from the United States of America from 1996 and during the last decade Mexico has imported more than 10.6 million tons per year, mostly yellow corn, although it has also been imported in the same period between 300 and 500 thousand tons of white corn. It is significant to note that $90 \%$ of corn purchased from the United States is transgenic. Transgenic corn is used in the production of more than 4 thousand products: for human and animal consumption (Bolívar Zapata et al., 2017).

The main objective of this article is not to discuss whether GMO foods are harmless or pose a risk to humans, but the importance of labeling products with GMO content, so that the final consumer has the power to decide what kind of products to buy or not, for their daily food. Currently more than 61 countries (Center for Food Safety, 2018) have legislated the legal framework to compulsorily labeling this type of merchandise, therefore, Mexico must legislate the corresponding laws before the society presses hard, as has happened in the United States of America and the European Economic Community.

This study was conducted with a sample of 2923 university students, and it was found that $58.40 \%$ of the total sample do not read the labels of the products they consume, $85.70 \%$ require the labeling of the characteristics of the content. In another important aspect $82.90 \%$ of students demand the advertising of the products made with GMOs. Finally, $82.90 \%$ demand that the Mexican Congress approve the necessary laws to force the companies to label the products with GMO. Comparing the results of the sample of university students from five universities in central Mexico with those of the study conducted in 2016, about the perceptions and attitudes towards transgenic products in Mexico (Montesinos-López et al., 2016). In order to discuss the results of the study carried out with the sample of the students of the five universities of central Mexico, in which a Likert scale questionnaire was used and to compare the results of the research carried out with the urban population of Mexico (Montesinos-López et al., 2016) in which a dichotomous questionnaire was used, it was necessary to add the results of the last three options of response of the Likert scale (occasionally, frequently and always), of question "Do you have the habit of reading the labels of the products your family consumes in the diet, before buying them?" and in this way we got that at least occasionally $71.6 \%$ of students read the labels, in relation to $63.25 \%$ of the Mexican urban population (Montesinos-López et al., 2016), the above is surprising, since it was expected that the percentage of university students that read the labels of products should be more higher, considering the academic level of the future professionals that would be responsible for human health and to 
produce plants and animals in Mexico. Both in the sample of university students $(94.20 \%)$ and the urban sample of the study of Montesinos-López, et al., (2016) (93.59\%), they propose that the label shows the characteristics of the product with GMO content. While, in the sample of university students $(92.20 \%)$ in relation to the urban sample $(93.69 \%)$ they propose that when promoting in any medium, a product with GMO content, the characteristics of the products should be made known to the individuals and finally, in the university students sample $(92.50 \%)$, while in the urban sample $(92.23 \%)$ agree that the Mexican government must legislate the corresponding legal framework to force the labeling of products with GMO content (Montesinos-López, et al., 2017). The above findings are consistent with studies conducted with students in Russia (Delmond et al., 2018), Kuwait (Nedaa \& Al, 2018) and in India ( Kajale \& Becker, 2013).

\section{Conclusions}

Regarding the habit of reading the labels before buying the products that the family consumes daily, the following is concluded: $6.40 \%$ of the students surveyed mentioned that they never read the information that is shown on the labels, $22.20 \%$ said that they rarely read the information on them, $29.80 \%$ occasionally read the information on the labels, $25.00 \%$ mentioned that they often read the information on the labels, and finally $16.60 \%$ said that they always read labels of the products their family consume in the daily diet. The students surveyed are from the following careers: medicine, nursing, nutrition, agronomy, veterinary, chemistry and business, and these results means that these students need to be informed and trained in this topic since in the near future they will be responsible for human health and the production of food with plants and animals for human consumption.

Also, we found that $85.70 \%$ of the sample that integrated the investigation answered that they want that the products produced with GMO, always show the characteristics of the content on the label. Regarding the promotion of transgenic products, the object of study considered that it is transcendental to inform the final consumer about its content of the products consumed by his family, since $82.90 \%$ revealed that the final consumer should always be informed about the content of the product they consume in his daily diet, by using different means of advertising to promote this type of product.

Finally, respondents concluded in relation to the importance of the Mexican government should generate laws to regulate the labeling of transgenic products, was observed that $82.90 \%$ agree that the Mexican government should legislate a legal framework to regulate the labeling of products made with GMOs, in such a way that the final consumer can made its decision on whether or not to buy the products with GMO that consumes daily.

\section{Acknowledgements}

To the Autonomous University of Querétaro, Autonomous University of San Luis Potosí, Michoacán University of San Nicolás de Hidalgo, Autonomous University of Aguascalientes and University of Colima, for participating in this research.

Emeterio Franco Pérez and Osval Antonio Montesinos López: Conceptualization, Methodology, Investigation, Resources, Writing - Original Draft, Supervision and Project administration. Sara Sandoval Carrillo, J Jesús García Martínez and Alberto Pastrana Palma: Writing - Review \& Editing., Osval Antonio Montesinos López and Josafhat Salinas Ruiz: Software, Validation and Formal analysis.

\section{References}

Bolívar Zapata, F. G., Herrera Estrella, L., \& López-Mungía Canales, A. (2017). Presencia de maíz transgénico de importación en México, 20 años de inocuidad en productos derivados para consumo humano y animal. Gaseta Digital UNAM, 6(4917), 4-5. $\quad$ Retrieved from

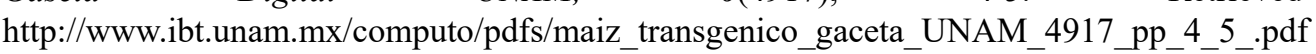

Bovay, J., \& Alstonb, J. M. (2018). GMO food labels in the United States: Economic implications of the new. https://doi.org/10.1016/j.foodpol.2018.02.013

Castellari, E., Soregaroli, C., \& Thomas, J. V. (2018). Food processor and retailer non-GMO standards in the US and EU and the driving role of regulations. Food Policy, 78, 26-37. https://doi.org/10.1016/j.foodpol.2018.02.010

Center for Food Safety. (2018). Long-awaited final regulations for GMO food labeling leave millions of Americans in the dark, USA: Center for Food Safety. Retrieved from https://www.centerforfoodsafety.org/press-releases/5487/long-awaited-final-regulations-for-gmo-food-labeli ng-leave-millions-of-americans-in-the-dark

Comité de expertos académicos nacionales del etiquetado frontal de alimentos. (2018). Sistema de etiquetado frontal de alimentos y bebidas no alcohólicas para una mejor salud. http://dx.doi.org/10.21149/9615 
De Beer, T., \& Wynberg, R. (2018). Developing and implementing policy for the mandatory labelling of genetically modified food in South Africa. National Research Foundation (South Africa), 1-7. https://doi.org/10.17159/sajs.2018/20170137

Delmond, A. R., McCluskeya, J. J., Yormirzoevb, M., \& Rogovab, M. A. (2018). Russian consumer willingness to pay for genetically modified food. Food Policy, 12(78), 91-100. https://doi.org/10.1016/j.foodpol.2018.02.004

González-Ortega, E. et al. (2017). Pervasive presence of transgenes and glyphosate in maize-deried food in Mexico. Agroecology and Sustainable Food Systems, 1461-1161. https://doi.org/10.1080/21683565.2017.1372841

Kajale, D. B., \& Becker, T. C. (2013). Determinants of consumer support for mandatory labeling of genetically modified food in India. British Food Journal, 115(11), 1597-1611. https://doi.org/10.1108/BFJ-12-2011-0302

Meemken, E. M., \& Matin, Q. (2018). Organic Agriculture, Food. Organic Agriculture, Food Security, and the Environment, 10, 39-63. https://doi.org/10.1146/annurev-resource-100517-023252

Montesinos-López, O. A. (2017). Actitud hacia el etiquetado en productos genéticamete modificados en la población urbana de México. Revista Iberoamericana de Contaduría, Economía y Administración, 6(12), 25-48. https://doi.org/10.23913/ricea.v6i12.91

Montesinos-López, O. A., Franco-Pérez, E., Luna-Espinoza, I., \& Aragón-Chávez, F. (2016). Percepciones y actitudes hacia los transgénicos en México. Primera ed. México: Pearson.

Nedaa,. A., \& Al, K. (2018). Attitudes Towards and Use of Nutrition Labels by Kuwait University Students. College Student Journal, 52(2), 215-226.

Ramírez, N. R. A., Sánchez, O. V. M., \& Mercado, S. M. V. (2016). Que expide la ley para el etiquetado de alimentos de la categoría orgánicos y transgénicos. México (México). Retrieved from http://sil.gobernacion.gob.mx/Archivos/Documentos/2016/02/asun_3333109_20160212_1455039370.pdf

Venus, T. J., Kalaitzandonakes, N., \& Wesseler, J. (2016). Lessons from EU Voluntary Labeling Schemes for GM-Free Processed Food Products. Organic and Conventional Foods, Natural Resource Management and Policy, 49(49), 379-386.

\section{Copyrights}

Copyright for this article is retained by the author(s), with first publication rights granted to the journal.

This is an open-access article distributed under the terms and conditions of the Creative Commons Attribution license (http://creativecommons.org/licenses/by/4.0/). 